\title{
Formas de Conhecimento, Informação e Políticas Públicas
}

\section{Eni Puccinelli Orlandi *}

Resumo: Neste artigo, refletimos sobre a relação entre informação, conhecimento e divulgação científica. O que nos leva a discutir a própria natureza das políticas públicas e do que seja a arte da política, quando pensamos uma sociedade do conhecimento e da informação. Com esta reflexão, visamos levar a compreender a necessidade que temos de um deslocamento na própria noção de política e nas formas de produção e circulação do conhecimento, quando se trata de levar em conta a sociedade, para não aprofundar ainda mais as divisões sociais. Palavras-chave: divulgação científica, informação/conhecimento, políticas públicas

Resumen: En este artículo reflexionamos sobre la relación entre información, conocimiento y divulgación científica, lo que nos lleva a discutir la propia naturaleza de las políticas públicas y de lo que es el arte de la política, cuando pensamos en una sociedad del conocimiento y de la información. Con esta reflexión buscamos llevar a comprender la necesidad que tenemos de un desplazamiento en la propia noción de política y en las formas de producción y circulación del conocimiento, cuando se trata de tomar en cuenta la sociedad, para no profundizar aún más las divisiones sociales. Palabras claves: divulgación científica, información/conocimiento, políticas públicas

Abstract: In this article, we reflect on the relations among information, knowledge and scientific divulgation, which lead us to discuss the very nature of public policies and what the art of politics is when we think a society of knowledge and information. With this reflection, our objective is to lead to the comprehension of our need for a displacement in policyitself and in the forms of production and circulation of knowledge when taking society in to account, to avoid deepening social divisions even more. Keywords: scientific divulgation, information/knowledge, public policies 


\section{Introdução}

Quando juntamos conhecimento e informação, em geral, resulta em uma leitura em que se faz uma mera associação entre os dois. Para um analista de discurso, que é a posição em que me situo, no entanto, há aí dois enunciados que aí fazem efeito: "Nossa sociedade é uma sociedade da informação (SI)" e "O sujeito de nossa sociedade é um sujeito do conhecimento". Sobejamente explorados, o primeiro, na relação com as novas tecnologias da linguagem e, o segundo, fazendo funcionar toda a discursividade foucauldiana da relação saber/poder.

No entanto, penso que podemos pensar esta relação de enunciados de outro modo. Aquele que pensa, por exemplo, a necessidade social de um discurso como o da divulgação científica que, como tenho afirmado (E. Orlandi, 2001), indica a exterioridade da ciência, ou seja, a necessidade que tem nossa sociedade que a ciência não se limite ao seu espaço de circulação mais restrito mas ganhe o espaço social mais amplo. Se exteriorize na sociedade. Ela sai de si, sai de suas condições mais próprias e ocupa um lugar no cotidiano dos sujeitos. Circula produzindo seus efeitos de "conhecimento". O sujeito lê/ouve x, logo, ele sabe que x. Ele está informado sobre a ciência. O que é diferente, explico eu (E. Orlandi idem) de: eu leio/ ouço $\mathrm{x}$ logo eu sei $\mathrm{x}$ (e não que $\mathrm{x}$, que é apenas notícia/informação sobre conhecimento e não conhecimento). Do ponto de vista técnico, produz-se a separação entre ciência e saber e a ilusão de seu recobrimento. Você não conhece $\mathrm{x}$, você sabe que x. É um efeito de informação, como disse. Mas é representado como autorizando esse sujeito a dizer que conhece. Essa é uma ilusão que faz parte do funcionamento de nossa sociedade com relação ao conhecimento. Ela funciona no imaginário de que saber que $\mathrm{x}$ é igual a saber $x$, daí que saber (informar-se) é ter conhecimento e este é poder; faz parte dessa ilusão, também, pensar que desse modo há mudança social no acesso ao conhecimento e assim por diante. E, embalados pelos mitos da mídia, achamos que estamos muito bem informados, sim senhor: "Hoje tudo se sabe. Acontece algo lá na China e na mesma hora já sabemos aqui na região do semi-árido baiano". Aí estar informado e saber vêm juntos. E somos sujeitos do conhecimento de uma sociedade da informação.

Como não penso que isto se passe assim, vou introduzir a questão do social através das políticas públicas, estas que dão ou não "acesso" ao conhecimento e à informação. 


\section{Políticas públicas?}

Ao pensar este tema que trata de conhecimento e políticas públicas, gostaria de falar sobre o que se tem considerado como público. Em geral, o que é público, assim como o que é de uso comum, popular, é concebido de modo pejorativo. No entanto - e aqui penso em uma pesquisa que fiz sobre a palavra povo (E. Orlandi, 2006) - se olhamos de forma diversa, a noção de povo, que está na base dos processos de significação de popular/público é uma noção projetiva, que acolhe as diferentes imagens que lhe são atribuídas - inclusive as pejorativas - mas que em seu real não se identifica exatamente com nenhuma. O "povo" é o fiel da balança, digamos. Permanece como o possível de uma nova (ou outra) ordem social em sua materialidade histórica. Permite a abertura do social para o que pode vir a ser. $\mathrm{O}$ povo é constituído por relações, por vínculos. $O$ popular é o que se faz no movimento, no plural. Ele é a dimensão pública, a da quantidade, onde convergência e divergência se cruzam.

Por seu lado, penso que a arte da política é a arte de pensar pelo outro, isto é, em termos discursivos, praticar o pensamento político é situar-se lá onde os sentidos se repartem. Há, pelo modo como a sociedade é regida, formas de estabilização desses sentidos em formações discursivas que fixam sentidos para o público e para as políticas públicas (cf. o que é "consenso" em E. Orlandi (org) 2010). Como disse, praticar o real do pensamento político é poder situar-se onde os sentidos se repartem e poder assim observar os limites impostos pelas formações discursivas, sendo sensível a outros sentidos para o que seja o público, o que nos leva a exercer outras práticas políticas, outros sentidos de social.

Portanto, não são evidentes nem o sentido de público, nem os sentidos das políticas públicas quando tomamos a perspectiva discursiva.

Além disso, para interferir na realidade é preciso compreendê-la. Para tanto, é preciso saber que saber comum está inscrito nas reivindicações que são feitas socialmente em face do conhecimento formal. E, em se tratando, de práticas de conhecimento, há três formas que se conjugam: o conhecimento conceptual, o conhecimento técnico e o que serve à administração. Daí a complexidade do conhecimento necessário para se exercer as políticas públicas, já que estas exigem as três formas de conhecimento que se recobrem: o como se concebe, o como se viabiliza pela tecnologia e 
o como se administra a demanda.

Passemos agora à questão do conhecimento e a relação entre os conhecimentos específicos e o saber comum investidos nas políticas públicas. Não podemos tampouco desconhecer que o saber comum mas também teorias formalizadas fundamentam interferências sociais. A análise de discurso é sensível ao fato de que conhecimentos diversificados permitem dimensionar a sociedade na história. Temos então que produzir formas de conhecimento com capacidade de resposta às demandas sociais (tanto em sua representação como participação). Ora, a resposta é para uma sociedade em movimento. Por isso insistimos que temos de ter a capacidade de projetar essas demandas na história para que elas signifiquem.

Se, de um lado, situações socialmente problemáticas são um sintoma da irrupção de novos sentidos do público (e logo de novas demandas sociais), de outro, as reivindicações de direitos também são um seu indício. No entanto como não podemos ficar atrelados somente a situações problemáticas e como nem sempre as reivindicações são ouvidas temos necessidade de teoria, de pesquisa no campo das políticas públicas para qualificar as formas de interferência. Como encontrar novos sentidos para a política social? Eis a questão que estamos nos colocando nessa reflexão.

Para refletirmos sobre esta questão, tomemos antes o como funciona a divulgação científica.

\section{Divulgação científica: estrutura e funcionamento}

Uma das características da divulgação é a maneira como lida com a variedade. Vejamos como isso dá quando o instrumento é o jornal.

Pensando a realidade do sujeito que é afetado pelo simbólico e pelo político, podemos observar a questão da variedade em um instrumento de mídia como o jornal, iniciando já pela sua variedade interna: temos notícias de várias naturezas, abrangendo desde o próprio político até o conhecimento. É este último que vai nos interessar aqui já que estamos pensando a divulgação científica.

Dois aspectos, quando tomamos a divulgação científica e o jornal nos retém a atenção: o fato de que um texto remete a outros textos e o fato de que o imediato faz ir para o não imediato.

Se refletimos sobre o fato de que um texto remete a outros temos a interessante questão que é a da relação de sentidos. Nesse caso, podemos 
considerar a relação entre jornais em torno da mesma notícia. É um exercício extremamente interessante o de expor o leitor à leitura de vários jornais falando da "mesma" coisa. Isto porque permite ao leitor compreender um aspecto importante do funcionamento da linguagem que é o de que ao dizer de modo diferente podemos estar significando diferentemente o fato em questão. Assim, o leitor deixa de se iludir com a transparência da linguagem. Ou seja, ele passa a perceber que a linguagem tem sua espessura semântica, tem sua ordem, sua materialidade. Em conseqüência, passa também a considerar que a relação da linguagem com a realidade é complexa, não havendo uma relação direta entre a palavra e a coisa. Isto o expõe a um olhar menos automatizado face à realidade.

Em relação ao fato de que o imediato faz ir para o não-imediato, podemos iniciar com um exemplo: a leitura sobre eleições, que esteve em pauta recentemente, por exemplo, pode levar o leitor a pensar mais demoradamente a política, sua importância na vida do cidadão, suas formas de significação na vida de cada um etc. Portanto, um acontecimento pode levar à reflexão de todo um processo de constituição da própria vida social do cidadão. Isto, pensado como instrumento de ensino de leitura pode ser explorado de modo muito produtivo em sala de aula.

Mas queremos falar da questão de como se estrutura a divulgação científica de modo a expor a maneira mesma como a forma do enunciado de divulgação científica funciona produzindo efeitos. É o que passaremos a fazer sem seguida.

\section{Divulgação científica: um modo de dizer}

A divulgação científica se representa como o alargamento de conhecimentos científicos de uma comunidade mais restrita para seu exterior. Esse movimento de um meio restrito para o grande público é a de uma função tida socialmente como necessária para o desenvolvimento das ciências. Segundo Roqueplo (1974), a missão de fazer penetrar no grande público os novos conhecimentos consiste em colocar sob forma acessível ao público o resultado das pesquisas científicas. Trata-se para nós de uma questão discursiva, ou seja, a de transpor um discurso existente em função de um novo interlocutor. Isso significa que se trata da reformulação de um discurso fonte em um discurso segundo. As operações que aí são investidas, na reformulação são: transferência, resumo, resenha, análises reformuladas 
em direção a um grupo social, mensagens reescritas em função de certo alvo etc. No caso da divulgação científica o trabalho da reformulação é explícito, ou seja, ele se mostra como tal, e isto faz parte dos efeitos que se espera do discurso da divulgação científica. Ele mostra os bastidores em que os efeitos da divulgação são produzidos. Aparecem assim as supressões, adições, substituições operadas na reformulação como parte do modo como estas manifestações se constroem no discurso segundo uma imagem da atividade enunciadora de que ele é produto. Ou seja, ele produz assim uma imagem, uma representação da sua própria produção. Esta representação faz parte do discurso de divulgação. Ele mostra sistematicamente como se passa de um discurso (o da ciência) a outro e o faz como forma de legitimar sua relação com a ciência. Ao contrário do discurso pedagógico ou científico que trabalha com definições, o discurso da divulgação científica vai trabalhar com a menção: não temos "as bactérias são..." mas "O autor $X$ diz que as bactérias são..." Ou de modo mais complexo é todo um resumo que refere, ou a série de publicações etc: "No ano passado, em Londres, a Sociedade de Proteção Ambiental, reuniu-se para fazer uma avaliação das pesquisas em torno da questão Y..." ou então "Mais de dois mil especialistas se reuniram em Brasília no CNPQ.(...) Na conferência inaugural, o cientista $X$ declarou que..."

Como diz J. Authier (1998) "muitas vezes é sob o fundo de conhecimentos clássicos convocados pelo divulgador, em uma primeira parte, sob um modo pedagógico, próximo do manual, que aparece o discurso feito sobre o acontecimento, objeto do artigo". Os parâmetros do ato de enunciação - pessoas, datas, lugares, modalidades e circunstâncias - estão presentes de maneira insistente. Por exemplo: "Por volta de 1965, dois pesquisadores americanos, o eletrofisiologista G. Shepherd e o citologista T. Reese (...) chegaram ambos a uma conclusão inesperada(...) Pouco tempo depois, a equipe de J. Dowling da Universidade J. Hopkins (EUA) póe em evidência ...”. As referências podem ser mais vagas - como: pensa-se, admite-se hoje, os especialistas consideram etc - mas estarão presentes de modo explícito construindo a remissão de um discurso a outro.

Temos uma variedade enorme de formas de representar a interlocução científica de um discurso para o outro. Um exemplo seria: "Galileu procurou manter dois de seus redatores durante toda a reunião para relatar aos leitores que precisam manter-se informados sobre....."

Temos, assim uma estrutura de três lugares a Ciência, o Divulgador e o Público leitor. O lugar da ciência, como diz Authier (idem), é ocupado por múltiplas pessoas que se exprimem concretamente identificadas. Esses numerosos nomes próprios, prestigiosos e intercambiáveis para 
o leitor padrão, asseguram, tanto ou mais talvez que uma informação, um efeito de real e uma animação do discurso da ciência, ao mesmo tempo em que sua autoridade produz uma garantia de seriedade na divulgação científica.

De todo modo, vemos sempre a reformulação se fazendo e isto se encena para o leitor de forma que ele possa apreciar as idas e vindas de um discurso de especialista para o discurso comum. O que lhe dá garantias de que ele está todo o tempo fazendo a travessia da ciência, embora não permaneça nela como o faz o especialista com sua metalinguagem.

Por outro lado, a relação entre os discursos - o da ciência e o do cotidiano - podem ser de vários tipos: de equivalência, de sobreposição etc. $\mathrm{E}$ assim o leitor vai seguindo os discursos produzindo uma maior ou menor distância entre eles. $\mathrm{E}$ as formas da reformulação são várias: introduzidas por aposto, por simples justaposição, por incisa. Sem esquecer que o vocabulário especializado tem emprego abundante e sistemático. Daí termos, por exemplo:

" $Z$, dito $Y$; $Z$ é chamado de y; o dispositivo $x$, quer dizer, o reservatório de z; o estojo, ou cápsula, que reveste o ADN viral; grupos em um só "cluster" - um cacho - que...; envolta por uma "caixa" protéica". Como vemos, é abundante o uso de aspas, de itálico, de traços, e outros expedientes diacríticos. O que ressalta em todos esses usos é o fato de que não esconde, ao contrário, dá visibilidade aos modos da reformulação. Se, de um lado, essa forma explícita de dizer garante que é de ciência mesmo que se está falando, ela produz ao mesmo tempo a imagem de que esse conhecimento "reformulado" é um conhecimento só aproximativo. Mas mesmo assim esse discurso cumpre uma sua função fática importante: ainda que aproximativo, ele garante que a comunicação se faça, entre diferentes interlocutores, garantindo a coesão social, dando aos leitores uma representação confortável de sua posição relativa à ciência.

Se pensarmos a situação escolar, o texto de divulgação científica deve cumprir sua função de não deixar se quebrar o elo de comunicação que este aluno estabelece, através destes textos, com a ciência.

Certamente há uma grande diferença entre o texto científico e o texto de divulgação científica. A escola é, ou seria, o lugar precípuo do texto científico, insubstituível na formação do aluno que assim se inicia nas diferentes metalinguagens das diferentes disciplinas. Mas o discurso de divulgação, garantindo a função fática da comunicação com a ciência, mantém o aluno "ligado" ao que é produto do processo científico, que é objeto do ensino formal. A relação com esses produtos, por sua vez, garante a 
coesão social. E é assim que se forma a opinião pública, social, sobre ciência e que permite aos leitores em seu conjunto participar dos rumos que toma a produção científica. Porque a divulgação científica reforça a existência e a representação social da ciência. $\mathrm{Na}$ escola, portanto, essa forma de discurso pode ser o modo de introduzir o aluno na produção científica, que, a partir daí, fará seus diferentes trajetos em diferentes níveis de conhecimento e especialização

No entanto, o que vemos, é a escola cada vez mais próxima em seus discursos e materiais do discurso da divulgação, da mídia, e cada vez menos investida do ensino da ciência, em um programa de leitura de textos de autores. Em um seu procedimento comum e rotineiro, a Escola procura facilitar, tornar mais "próximo" (?) o discurso do cientista do discurso midiático ou do senso comum, o que é uma contradição pois, para isso, o aluno não precisa ir para a Escola. Sobretudo com as tecnologias que hoje circulam.

\section{Um deslocamento possível?}

As formas de conhecimento podem ser diversas, diferentes dos saberes já legitimados e as políticas públicas podem encontrar (novos) meios de torná-las acessíveis.

Há uma aparência de variedade homogênea, tanto por parte da sociedade como do conhecimento. Que é apenas aparência mas tem sua eficácia, como todo imaginário, pelo funcionamento da ideologia.

As formas de gestão para que haja a produção da homogeneidade se dão pela produção de técnicas materiais (que incluem a física e a biofísica) assim como a série de técnicas de gestão social do indivíduos: marcá-los, identificá-los, classificá-los, compará-los, colocá-los em ordem, em tabelas, reuni-los e separá-los, a fim de colocá-los no trabalho, a fim de instruí-los, de fazê-los sonhar, de protegê-los, de vigiá-los, de levá-los à guerra etc. Essas são propriedades que se inscrevem transparentemente, em uma descrição adequada do universo (tal que este universo é tomado discursivamente nesses espaços) com uma série de evidências lógico-práticas de nível geral (constituem um saber). Estas são também formas de gestão e de produção de uma aparência lógica estável e homogênea, um espaço administrativo (jurídico, político, econômico). Mas se estas formas de gestão funcionam é porque a elas corresponde uma forma de sujeito que lhes é 
sensível: o sujeito pragmático.

\section{Os sujeitos e a gestão dos saberes: uma questão pragmática}

O sujeito pragmático - isto é, cada um de nós, os "simples particulares" face às diversas urgências da vida - tem por si mesmo, diz M. Pêcheux (1997), uma imperiosa necessidade de homogeneidade lógica (conhecimento estabilizado): isto se marca pela existência dessa multiplicidade de pequenos sistemas lógicos portáteis que vão da gestão cotidiana da existência (por exemplo, a carteira, as chaves, a agenda, os papéis etc) até as grandes decisões da vida social e afetiva (decido fazer isto e não aquilo etc) passando por todo o contexto sócio-técnico dos aparelhos domésticos (que sabemos usar, que quebramos, que consertamos etc).

Nesse espaço de necessidade equívoca, misturando coisas e pessoas, processos técnicos e decisões morais, modo de emprego e escolhas políticas, toda conversa (desde o simples pedido de informação até a discussão) é suscetível de colocar em jogo, diz Pêcheux (idem) uma bipolarização lógica das proposições enunciáveis. De nada serve negar esta necessidade (desejo) de aparência, veículo de disjunções e categorizações lógicas: essa necessidade universal de um "mundo semanticamente normal", isto é, normatizado, começa com a relação de cada um com seu próprio corpo e seus arredores imediatos. E também não serve de nada negar que esta necessidade de fronteiras coincide com a construção de laços de dependência face às múltiplas coisas-a-saber, consideradas como reservas de conhecimento acumuladas, máquinas de saber contra as ameaças de toda espécie: o Estado e as instituições funcionam freqüentemente - pelo menos em nossa sociedade - como pólos privilegiados de resposta a esta necessidade ou a essa demanda, segundo M. Pêcheux (ibid.). Eu acrescentaria que o discurso da divulgação científica é a forma privilegiada de resposta a essa necessidade dos sujeitos pragmáticos de uma sociedade da informação em que o conhecimento ocupa esse lugar de organização, de gestão pública.

$\mathrm{O}$ que quero dizer com isso é que o conhecimento, assim concebido, e funcionando ideologicamente desse modo, é elemento estruturante de base do sistema capitalista contemporâneo.

As coisas a saber representam assim tudo o que arrisca faltar à felicidade (e, no limite, à simples sobrevida biológica) do sujeito pragmático: isto é, tudo o que o ameaça pelo fato mesmo que isto exista (o fato 
de que seja real); não é necessário ter uma intuição fenomenológica, uma pegada hermenêutica ou uma apreensão espontânea da essência do tifo, diz M. Pêcheux (ibid.), para ser afetado por essa doença; é mesmo o contrário: há coisas a saber (conhecimentos a gerir e a transmitir socialmente), isto é, descrições de situações, de sintomas e de atos (a efetuar ou evitar) associados às ameaças multiformes de um real do qual ninguém pode ignorar a lei - porque esse real é impiedoso.

Falando do projeto de um saber que unificaria esta multiplicidade heteróclita das coisas a saber em uma estrutura representável homogênea, M. Pêcheux (idem) diz que esse projeto responde com toda evidência a uma urgência tão viva, tão universalmente humana, ele amarra tão bem em torno do mesmo jogo dominação/resistência os interesses dos sucessivos mestres desse mundo e os de todos os condenados da terra que o fantasma desse saber eficaz tende historicamente a se materializar por todos os meios: o momento da escolástica aristotélica, o momento moderno contemporâneo do rigor positivo, no contexto histórico da constituição, enquanto ciências, da física, da química e da biologia, associado è emergência de uma nova forma de Direito e um novo lance do pensamento matemático (apoiado nas ciências exatas), e o momento do marxismo que pretende produzir as leis dialéticas da história e da matéria. $\mathrm{O}$ neo-positivismo e o marxismo formam assim as epistemes maiores de nosso tempo, diz o autor, tomadas em um encavalamento parcialmente contraditório em torno à questão das ciências sociais e humanas; tendo no centro a questão da história, isto é, a questão das formas de existência possível de uma ciência da história.

Se pensamos a análise de discurso, nossa posição é de que não pode existir essa ciência régia do real. Toda ciência tem a ver com a linguagem e com as formas de poder em que a sociedade tem sua formação. Se assim é, uma forma de ciência homogênea certamente deixaria de fora grande parte da população. Deixaria de fora o que chamamos de sensocomum.

Ora, se pensamos o próprio conhecimento de outra maneira e se atentamos ao fato de que a linguagem - e as novas tecnologias de linguagem - podem-se organizar diferentemente, é o próprio movimento da interpretação que pode ser trabalhado. Pensando o conhecimento como discursos, podemos esboçar novas formas de disciplinas que, na sua dispersão, atinjam a sociedade em seu todo. "Restituir algo do trabalho específico da letra, do símbolo, do vestígio, era começar a abrir uma falha no bloco compacto das pedagogias, das tecnologias (industriais e bio-médicas), dos humanismos moralizantes ou religiosos: era colocar em questão essas ar- 
ticulação dual do biológico com o social (excluindo o simbólico e o significante)." Trata-se, para além da leitura dos grandes textos (da Ciência, do Direito, do Estado) de se pôr na escuta das circulações cotidianas, tomadas no ordinário do sentido. E sobretudo correr o risco do equívoco, do heterogêneo, do des- organizado. Mostrar os rituais ideológicos embutidos nos discursos filosóficos, em enunciados políticos, nas formas culturais e estéticas e, por que não, científicas. É preciso tomar o discurso pelo que ele é: um índice potencial de uma agitação nas filiações sócio-históricas de identificação, já que ele é ao mesmo tempo efeito dessas filiações e um trabalho de deslocamento em seu espaço. O que M. Pêcheux (idem) nos propõe é ouvir de outro modo, é atentar ao fato de que tanto a ideologia como a linguagem têm falhas, funcionam pela falha. São capazes de rupturas, de desorganização, de equívoco.

Voltemos sobre nosso objeto: o conhecimento filiado a instituições e gerido pelo Estado. Há sempre a possibilidade de uma agitação nesse estado de coisas.

Entrando no campo mais direto das políticas públicas, podemos dizer que o Estado responde diretamente ao imaginário da Ciência Régia, reproduzindo o estado do saber (dominante) e o do não-saber (senso-comum). Interferir nesse estado de coisas é desmontar essa idéia de ciência régia e responder com conhecimentos específicos - produzidos pela pesquisa - necessários não só à sobrevivência como também ao movimento (o que chamam desenvolvimento?) - por que não dizer felicidade? - da população. $\mathrm{E}$ isto se faz com pesquisa e com conhecimento social. Conhecimento que a análise de discurso é capaz de produzir, porque desloca o olhar leitor, ou seja, expõe o sujeito a outros sentidos.

Por seu lado a Universidade, ou qualquer instituição "guardiã" do conhecimento e que o Estado assim autoriza, deve criar as condições para que, de um lado, novas formas de conhecimento sejam produzidas e, de outro, novos modos de inserção de conhecimento na sociedade sejam estimulados, acolhidos. E, a meu ver, isto envolve de maneira radical os modos de fazer pesquisa nas instituições e a própria relação das instituições com a sociedade. O que, em suma, significa que essa proposta de novas formas de políticas públicas face ao conhecimento, exige a prática de outras/ novas discursividades, uma vez que o discurso de divulgação, tal como se estrutura e funciona, como pudemos ver, não se coloca, face a política, no lugar da arte de pensar pelo outro, como deveria ser. Portanto, não desloca nem inaugura outras formas de relação da sociedade com o conhecimento, deixando-o sempre em seu mesmo lugar: o que faz (a) falta. Aprofundando 
as divisões sociais, sem significá-las.

\section{Referências}

J. Authier-Revuz. Palavras Incertas. Campinas: ed. Unicamp, 1998.

E. Orlandi. "Divulgação Científica e Efeito Leitor: uma política social urbana". In: E. Guimarães. Produção e Circulação do Conhecimento - Estado, Midia, Sociedade. Campinas: Pontes, 2001.

E. Orlandi. Cidade dos Sentidos. Campinas: Pontes, 2004.

. A noção de povo que se constitui em diferentes discursividades. In: SILVA, Soeli M. S. da (org). Sentidos do Povo. São Carlos: Claraluz, 2006.

M. Pêcheux. Discurso: Estrutura ou Acontecimento. Campinas: Pontes, 1984.

J. Roqueplo. Le partage du savoir - science, culture, vulgarisation. Paris: Seuil, 1974.

* Eni Puccinelli Orlandi

Doutorado na USP e em Paris/Vincennes (sanduiche) em 1976, pós doutora e professora visitante em várias instituições francesas (Univ. de Paris VII, ENS, Paris XIII, EHESS), na Suiça (Lausanne) e na Inglaterra (Lancaster). Coordenadora do Laboratório de Estudos Urbanos da Unicamp e do Mestrado de Ciências da Linguagem na Univás (MG).

\section{E-mail:}

enip@uol.com.br 